\title{
How Can Accessibility for Deaf and Hearing-Impaired Players be Improved in Video Games?
}

\author{
Robert Costello, Newcastle College University Centre, Newcastle upon Tyne, UK \\ Murray Lambert, Newcastle College University Centre, Newcastle upon Tyne, UK \\ Florian Kern, Newcastle College University Centre, Newcastle upon Tyne, UK
}

\begin{abstract}
This research investigates how the accessibility of video games can be improved for deaf and hearingimpaired players. The journal is divided into several areas, first, examining the use of subtitles and closed captions used in video games; and second, how visual cues can be used to provide better accessibility for deaf and hearing-impaired gamers. This includes effectively creating suitable atmospheres and mood in games through lighting as well as having a varied environment that prevents the players from getting bored with the setting of a game and finally exploring current best practices within the gaming industry. Through this research data the issues with accessibility can be found as well as how a lack of accessibility affects deaf and hearing-impaired gamers. Research from this investigation supports some of the evidence from other researchers in the field that accessibility features for deaf and hearing-impaired can be considered and implemented.
\end{abstract}

\section{KEYWORDS}

Accessibility, Deaf, Hearing-Impaired, Video-Games

\section{INTRODUCTION}

As video games are an ever-growing industry breaking down accessibility barriers to provide entertainment through this platform to as many people as possible allows for broader audiences and inclusion of more people into this medium. Gamers with disabilities are increasingly part of what is an evolving and dynamic expanding growing community as, UKIE points out " $32 \%$ of UK players play mobile, console and PC games. In 2016, there were $31.6 \mathrm{~m}$ players in the UK, approximately $50 \%$ of the total population" and "in 2017, 32.4 Million people played games in the UK" (UKIE, 2018). Previous literature within the field of disabilities and accessibilities have focused on establishing modern technologies to assist and bring forward successful ways of integrating tools to controllers, as a way of providing much needed engagement. It is this aspect of engagement, that individuals, who are disabled or have accessibility issues, will miss out on the full immersion and realism of the experience (Prates, and Chaimowicz, 2011; Dong, 2016; Beeston, Power, Cairns, and Barlet, 2018). Due to the advancement of technologies like that of Virtual Reality (VR), we can assist individuals with visual and audio feedbacks. Human Computer Interaction (HCI) can bring a whole lot more to support the different scenarios and participants, within the gaming world (Dong, 2016; Costello, 
2018). According to Centers for Disease Control and Prention (CDC), "More than 3.4 million (3\%) Americans aged 40 years and older are either legally blind (having visual acuity [VA] of 20/200 or worse or a visual field of less than 20 degrees) or are visually impaired (having VA of 20/40 or less)" (CDC, p1), and to add additional information to this, the American Foundation for the Blind (AFB), indicates in 2016, that "from January 2016 there are approximately 63,657 U.S. children, youth, and adult students in educational settings who are legally blind" (AFB, 2017, p. 2). The Royal National Institute of Blind People (RNIB) indicates in 2016, that certain games can support visually impaired players, like that of First Person Shooters (FPS), Fighting Games, Action Games, etc. However, as long as the computer games have a way of communicating to the player, through aspects of sound cues, to assist in their impairments, then they can immerse themselves. The National Library Service for the Blind in the USA (2018) indicates that "many resources are available for gamers with disabilities. Computer programmers have developed audio games (or audio adaptations of games) that can be played by people who are blind or visually impaired" (National Library Service for the Blind, 2018, p1). In 2012, a set of guidelines were published to assist the gaming industry that explored aspects of supporting features for disabilities and accessibility for gamers from sensitivity to button controls to sudden unexpected movement or events, (Game Accessibility Guidelines, 2012). According to Game Accessibility Guidelines (2012) \& Alcázar, Luján-Mora, and Salvador-Ullauri, (2018), accessibility means avoiding unnecessary barriers that prevent people with a range of impairments from accessing or enjoying game(s). Maenpaa's (2014), and Alcázar and Luján-Mora (2017) suggests there is evidence and research to show there are general guidelines and recommendations for construction of accessibilities features into games; however, there should be a greater influence from the gaming industry that still needs to be formalised.

This greater influence can have a major impact not just with accessibility but with other health aspects as pointed out by Morelli, Foley, and Folmer (2010). Through addressing accessibility issues alone within games, individuals with health issues like obesity, poor self-related health issues (diabetes and heart diseases), to visual impairments could be addressed and engaged. These accessibilities could address issues of social interactions; support physical activities to improvement cognitive development and awareness. These approaches as adopted by Morelli et al., (2010) can be seen as "exergames", but lays downs some of the foundation for Game Accessibility Guidelines (2012) \& Alcázar, LujánMora, and Salvador-Ullauri, (2018) that visual cues or subtitles and captions are needed to help steer the player. The research carried out by Morelli et al., (2010) does indicate the use of audio and visual cues to assist the player in a variety of different features relating to the game designs, from "speech cues, number of pins hit after each throw and score" (p. 4).

Video games are a very flexible platform that allows users to interact with it in many ways. According to the Barlet, and Spohn, (2012) and The National Library Service for the Blind (2018), instead of approaching accessibility through universal design it is more appropriate to acknowledge that $100 \%$ inclusion is not feasible, but access to entertainment is. Heron, (2012) agrees with Barlet, and Spohn, (2012) and suggests that it is sometimes "hard to convince people that they should be employing more disabled developers and in-house testers" so that they can access accessibility better within the game development stage. As Heron (2012), point outs, adding in subtle things into games development from using cue sounds, or large text, to close captioning "is vital for creating an accessible game for the deaf" (p. 3). Another important aspect is that closed captions should be used throughout the whole game to assist the player with multiple needs. Providing game developers with universal design guidelines would prove difficult to achieve especially for small developers. Therefore, the study investigates how already existing features such as subtitles and closed captions should be implemented and could be improved. As television and video games share some similar aspects in the way information is conveyed to a user, such as story elements through dialogue, investigating guidelines provided in television can provide a basis to improve video game accessibility in these aspects for deaf and hearing-impaired gamers. As Lahav, Gedalevitz, Battersby, Brown, Evett, and Merritt (2018) point out, having some sort of navigational clues or capabilities to substitute their 
other sensorial channels, would provide compensatory alternative method in which they can derive feedback from, or adapt tactile information from the current gaming scene. According to Barlet and Spohn's (2012) research, non-audio cues found within games do allow gamers to interpret important game information and can act as an alternate warning, which would assist hearing-impaired players too. Further research by Barlet \& Spohn, (2012) would indicate that the use of closed captions, that has the ability to change fonts and text colours as well as including ambient noises as text output and alternative reactionary within the gaming environment has the ability to improve accessibility for deaf and hearing-impaired gamers. Hamilton, (2015) agrees with the research indicated by Barlet and Spohn (2012) and suggests that best practices for subtitles should be the use of high contrast between text and background, avoiding to much text and using a large enough text size. As Duffy, Price, Volpe, Marshall, Berthouze, Cappagli, Cuturi, Balzarotti, Trainor and Gori (2017) point out, games have the abilities to "exploit different sensory modalities, offering opportunities for new ways of thinking and processing information, and opening new avenues for creativity" and provide the gamer with the abilities of "competitions, goals, rules, challenges, choices and fantasies," which can help steer their own motivations needs (Costello, 2017; Costello \& Lambert, 2018).

The research in this paper, will be exploring a variety of different areas of Human Computer Interaction (HCI), Subtitles and close captioning, Television subtitles guidelines, Visual cues and Fighting Enemies and what can influence the game designs.

\section{RELATED WORK}

The literature review investigates different areas of games such as human-computer interaction, game design and also accessibility of video games to deaf or hearing-impaired players.

\subsection{Subtitles and Close Captioning}

It is vital that the story and fundamental information are conveyed to the player in some sort of way. A game could be using something like cut scenes or audio-logs but also written text such as letters and notes to tell the player a story. If audio is used to deliver story elements it is necessary for a game to include subtitles so deaf and hearing-impaired players are able to follow the story. Regarding subtitles and closed captions Barlet and Spohn state (2012) \& Heron (2012), in order to make a game accessible to deaf and hearing-impaired gamers it must: "have subtitles present and closed captions for ambient noise included as well as identifying the speaker" (Barlet and Spohn, 2012, p. 5). In addition, Hamilton (2015) builds on this by giving some basic practices for subtitles: high contrast between text and background, not too much text on screen at once and using a large enough text size. It can be noted that they are valid points as games such as Half Life 2 (Valve Corporation, 2004), have successfully implemented those functions. However, there are still a lot of games that do not implement subtitles or follow these best practices and guidelines, Ubisoft (2013) for a bad example from Assasins Creed 4. The problem lies within there not being a set guideline for games on subtitles and closed captions.

As video games do not have guidelines on accessibility it is not required for them to implement features such as subtitles and closed captioning. Implementing such guidelines to the games industry could greatly improve the way subtitles and closed captions are used in video games. Besides Griffiths (2009) states that because there are no guidelines for video games, a lot of games still don't implement subtitles effectively. In contrast the Able Gamers Foundation (2012) states that accessibility through universal design is not feasible. If accessibility guidelines were to be provided to developers, they would need to be dynamically fluid as well as some games do not require subtitles or closed captioning because of the style of game they are. Therefore, guidelines would need to be adjusted accordingly so games that do not require subtitles and closed captions do not need to include those. Nevertheless, they should provide other accessibility features to provide an enjoyable experience for deaf and hearing-impaired gamers. 
There is a lot of potential in using closed captions. When audio is used to deliver certain information in a game closed captions need to be used on the contrary to display this information to deaf and hearing-impaired gamers too. According to Barlet and Spohn (2012), for players with a hearing impairment ambient noises must be captured in text on the screen, especially in games where enemies/NPC's have sounds designed to be an early warning system. On the other hand, Galitz (2002) points out that repeated and excessive stimulation can fatigue the sensory storage mechanism of a person, making them less attentive and unable to distinguish what is important. This makes it vital to decide what noises need to be close captioned as the player should not be overwhelmed by the amount of text displayed on screen as they can miss out on some other vital information. Galitz' (2002) expands further on their research by indicating that player can get easily distracted from the gameplay through having overwhelming amount of information within the gaming world. Therefore, the industry or researchers need to consider what sounds are necessary to be captioned to set the mood and atmosphere of the environment or what information is necessary to be displayed to provide fairness to deaf gamers.

\subsection{Television Subtitles Guidelines}

Television and video games are two forms of media entertainment that are related to a certain degree as both rely on moving images, sound, speech and story. As television has set guidelines regarding the use of subtitles and closed captions, looking at how they are designed is going to provide some valuable insight. Hamilton (2015) states to achieve correct timings, words sometimes need to be trimmed but must be done to not harm comprehension. Looking at the BBC's guidelines for online television there are further points raised such as to avoid changing the form of a verb, editing speech before knowing the amount of time available as well as not editing words that can be lipread (Williams, 2009). Additionally, Williams (2009), states that research in eye movement shows that hearing-impaired viewers make use of visual cues from faces of speakers. This is something not considered as indicated by Hamilton (2015) but as animations become more realistic and lifelike it should become vital to consider this for games too. However, if a game is not styled towards realistic looks but rather a certain art style this might not be necessary. In contrast considering that some games strive towards realistic animations not editing words that can be lip-read creates more immersion for deaf and hearing-impaired gamers. In regard to presentation Williams (2009), states that each subtitle should consist of no more than three lines and each line between 32 and 34 characters. Hamilton (2015) agrees with Williams (2009), and also adds that new lines should be added from the bottom of the text queue. This allows the reader to understand and read the text in a logical manner. Using more detailed guidelines that are provided in television and adjusting them for video games can greatly improve the effectiveness of subtitles.

\subsection{Visual Cues}

According to Barlet and Spohn (2012) letting players change text colour allows them to set visual cues for where information is coming from. Having this functionality would allow deaf and hearingimpaired gamers to adapt the colour of closed captions to indicate different information. This can be very useful in making it easier to establish what kind of sound is captioned or where it is coming from as well as indicating who is talking in a dialogue. However, as Galitz (2002) states that simply adding colour to a screen could impact on user experience and when used improperly could distract the viewer and interfere with the displayed information. Therefore, letting gamers adjust the colour of text could lead to an overwhelming display and the task of colour coding information should be left to the designers of games. Barlet and Spohn (2012) identify that all games should have colour blind options. Taking into consideration that some deaf and hearing-impaired gamers might also have colour blindness this sort of colour adjustment should be allowed to be made by the players. This allows designers to implement the function of a colour blindness mode and lets the player choose whether or not to use it. 
Just like audio, lighting is used in video games to create atmosphere and establish the mood in a scene. According to Feil and Scattergood (2005) using the correct sounds for an environment can greatly increase the immersion a player feels. Immersion is a very important part of gameplay, if a player does not get immersed into a game the experience will be impacted and the game is not as enjoyable. Feil and Scattergood (2005) indicates that setting the mood and enhancing the ambiance of a game can greatly help immersing the player. If audio is used to create ambience and mood in a game but is not represented visually a deaf gamer does not get the same immersion as a hearing player would. If the composition of lights does not set the mood it is supposed to, the experience of going through the environment will not be coherent to the player. De Jong (2008), states that contrast of lighting in an environment can improve the results in immersive of a game and designers must use different kinds of lights and lighting colours to create an interesting and immersive environment visually.

One of the lighting examples recommended by De Jong (2008), can be found in Dark Souls 3, which creates a spooky atmosphere (FromSoftware, 2016). If this is the case a Deaf gamer is going to be more immersed in the game through an unpredictable and exciting composition of lighting in the environment.

Not every game creator is going to have the time and resources to spend lots of effort on creating mood and atmosphere through lighting. Additionally, it might not be necessary for a game to use lots of lighting to create atmosphere. More so Maenpaa (2014) expresses that if visual effects are to be optimized for deaf and hearing-impaired gamers, developers should keep changes to a minimum, especially if the product has been released already, as well as the changes need to mirror the style of the game. There are many considerations that need to be made when designing lighting to create mood and atmosphere in a game. Additionally, creating a suitable atmosphere through lighting in a game takes extra time and resources to create. Therefore, game creators have to decide how lighting is going to be implemented, what is going to be their use and what are the resources and time it is going to take to implement them effectively. Although if done correctly they can have a great effect to create immersion for the player.

\subsection{Fighting Enemies}

The experience of fighting an enemy needs to be coherent to the player. Sometimes enemies give an audio indication before they attack or are nearby. For a Deaf player the problem is that sometimes there is no visual indication in what an enemy is about to do. If an enemy spawns outside of the player's view but has an audio cue to warn the player that there is an enemy nearby it can be problematic for a deaf gamer to fight this enemy. They can be taken by total surprise as they don't know the enemy is close by. In regard to this problem Rogers (2010) indicates that as first person cameras only show a player's point of view, only the front is seen and the player does not see a pursuant and therefore does not get an indication. In the case that an enemy is supposed to surprise the player there should not be an unfair advantage for a deaf or hearing-impaired player. So, if there is an audio indication for this enemy it should also be indicated visually even if it is out of the player's view.

If an enemy is not designed to actually surprise the player, they need to be able to anticipate the enemy. This is especially true during combat situations. According to Rogers (2010) telegraphing an enemies actions to the player allows anticipation of what an enemy is about to do, visually this is best done through an animation of the enemy and could be something such as: cocking a fist back to punch, growling or yelling before attacking or a weapon or a spell that charges up before firing. Rouse (2005), suggests the fun of playing a game quickly wanes when the player can certainly know what enemies are going to do at any given second because players want the AI to surprise and to defeat them in ways they had not anticipated. As indicated by Rouse (2005) and Rogers (2010) consideration must be observed for non-player characters (NPC's) as enemies will need to give indications of what they are about to do but not the patterns of their actions need to not be easily predictable. Showing these anticipated actions visually allows both hearing and deaf players to have a similar experience when fighting an enemy. 


\section{RESEARCH METHODS}

\subsection{Chosen Methods}

The conducted research uses a mixed methods approach. Tashakkori and Teddlie (2003) state that a major advantage of mixed method research is that it enables simultaneous answering of confirmatory and exploratory questions and so verifies and generates theory in a study. This study explores the accessibility of games for deaf gamers as well as confirms what can be improved to avoid this issue.

The first part of the research consists of qualitative exploratory research. Cresswell (2007, p. 37) states that a qualitative approach is inductive and analysis of qualitative data establishes themes or patterns. Analysing the data provides direct feedback about accessibility features of video games from deaf and hearing-impaired gamers. To ensure a sample data set for a preliminary investigation to be used, 32 participants with mixed disabilities will be used, please see Table 1: Participant Demographics. Furthermore, an analytical approach is also required to analyse the quantitative data gathered from the survey Dudovskiy (2017) to assist with critical thinking while assisting with meaningful data.

Twelve of the 32 participants did not have any disabilities, so multiple approaches were taken, for example: dark sun glasses to tint out visual screen; tunnel vision glasses were used to limit again vision perception and finally sound proof ear phones, to make sure no immerse feeling could be sensed. The test participants were broken up and divided up into 3 key areas and there were (mild vision loss, or near-normal vision; moderate visual impairment, severe visual impairment, or severe low vision; - Mild Hearing Loss, Moderate Hearing, Severe Hearing). The Participant size insured that there was a suitable sample size for the preliminary investigation into the topic area (Betke, Gips, and Fleming, 2002; Linden, Habib, and Radojevic, 1996). The research associated with the journal was conducted from October 2017 - September 2018. The next section will explore the finding from the data investigation.

\section{FINDINGS}

\subsection{Testing Game Accessibility}

11 different games were tested on their accessibility for deaf and hearing-impaired players. Although most games are playable without sound the gameplay experience is affected a lot of the time as accessibility features are not implemented well. As Maenpaa (2014), states hearing players use sound as an important cue and visual cues are the necessary counterpart for non-hearing gamers. It was necessary to find how accessibility features affect playing games without sound. Table 2 'testing games' below displays the results from exploring accessibility.

Table 1. Participant demographics

\begin{tabular}{|c|c|l|}
\hline Sex & Group Age & \multicolumn{1}{|c|}{ No. of Participants } \\
\hline M & $18-25$ & 1 \\
\hline F & $18-25$ & 8 \\
\hline M & $26-35$ & 5 \\
\hline F & $26-35$ & 3 \\
\hline M & $36-45$ & 2 \\
\hline M & $46+$ & 0 \\
\hline
\end{tabular}




\subsection{Game Observations Analysis}

Testing accessibility for deaf players revealed that a range of accessibility features are implemented but some top title games have not fully implemented best practices. There is a definite relation between subtitles and whether the story can be followed coherently, such as in Hellblade: Senua's Sacrifice where the speakers of dialogue are not shown on screen a lot of the time. When the game swaps between speakers it does not indicate who is talking; it makes the dialogue confusing and affects the experience of the story (Ninja Theory, 2017). Depending on the genre, games have different availability of accessibility features such as strategy games offering players more visual cues in comparison to other genres. Events such as an enemy attack are visually represented with either notification icons or closed captions like 'Stellaris' (Paradox Interactive, 2016) and Age of Empires II HD (Microsoft, 2012).

First person shooters sometimes use an arrow indication of where an enemy is and if the player been spotted within a mini-map in the corner of the display to give a visual indication of enemies, for example ELEX (Piranha Bytes, 2017). None of the games were unplayable without sound but through present issues the gameplay experience was impacted in different ways. Schell (2008) states that because often games contain a lot of information which needs to be displayed at the same time the design of communication between game and player requires a lot of thought. During the testing it came to light that importance of communication between player and game is considered in the development process. This is the case as all of the games had a lot to all necessary information to play the game displayed on the HUD or in a different way.

Table 2. 'Testing games' for accessibility

\begin{tabular}{|c|c|c|c|c|c|c|c|c|}
\hline $\begin{array}{l}\text { Game Name } \\
\text { and Platform }\end{array}$ & Genre & $\begin{array}{l}\text { Subtitles } \\
\text { Yes } \\
\text { No }\end{array}$ & $\begin{array}{l}\text { Subtitle } \\
\text { Structure } \\
1 \text {-Bad } \\
2 \text { - Moderate } \\
3 \text { - Good } \\
4 \text { - Excellent }\end{array}$ & $\begin{array}{l}\text { Necessary Info } \\
\text { displayed } \\
\text { visually } \\
\text { 1-None } \\
\text { 2-Some } \\
\text { 3-Most } \\
\text { 4-All }\end{array}$ & $\begin{array}{l}\text { Closed } \\
\text { Captions } \\
1-\text { None } \\
\text { 2-Some } \\
\text { 3-A lot } \\
\text { 4-All sounds }\end{array}$ & $\begin{array}{l}\text { Visual cues to } \\
\text { aid players } \\
1-\text { None } \\
2 \text { - Basic } \\
3 \text {-Some } \\
\text { extra } \\
4 \text {-A lot }\end{array}$ & $\begin{array}{l}\text { Story } \\
1- \\
\text { Incoherent } \\
2- \\
\text { confusing at } \\
\text { times } \\
3 \text {-Coherent } \\
\text { most of the } \\
\text { time } \\
4 \text {-Coherent }\end{array}$ & $\begin{array}{l}\text { Playability } \\
1-\text { not } \\
\text { playable } \\
2-\text { Hard } \\
\text { 3-Moderate } \\
\text { 4- Fair } \\
5 \text { - Very Fair }\end{array}$ \\
\hline $\begin{array}{l}\text { Hellblade: } \\
\text { Senua's } \\
\text { Sacrifice } \\
\text { - PC }\end{array}$ & $\begin{array}{l}\text { Third person } \\
\text { Action } \\
\text { Adventure }\end{array}$ & Yes & 1 & 3 & 2 & 3 & 1 & 3 \\
\hline $\begin{array}{r}\text { Subnautica } \\
- \text { PC }\end{array}$ & $\begin{array}{l}\text { First Person } \\
\text { Sandbox } \\
\text { Adventure }\end{array}$ & Yes & 4 & 3 & 1 & 2 & 4 & 3 \\
\hline $\begin{array}{c}\text { Dark Souls } 3 \\
-\quad \text { PC }\end{array}$ & $\begin{array}{l}\text { Third Person } \\
\text { Action RPG }\end{array}$ & Yes & 3 & 4 & 1 & 3 & 3 & 3 \\
\hline $\begin{array}{r}\text { Far Cry } 3 \\
-\quad \mathrm{Pc}\end{array}$ & $\begin{array}{l}\text { First Person } \\
\text { Open world } \\
\text { shooter }\end{array}$ & Yes & 2 & 4 & 1 & 3 & 2 & 3 \\
\hline $\begin{array}{c}\text { State of Decay } \\
-\quad \text { PC }\end{array}$ & $\begin{array}{l}\text { Open World } \\
\text { Zombie } \\
\text { Survival RPG }\end{array}$ & Yes & 3 & 4 & 1 & 3 & 4 & 4 \\
\hline $\begin{array}{l}\text { Wolfenstein } \\
\text { The New } \\
\text { Order } \\
\text { - PC }\end{array}$ & $\begin{array}{l}\text { First Person } \\
\text { shooter }\end{array}$ & Yes & 3 & 4 & 1 & 3 & 4 & 4 \\
\hline $\begin{array}{l}\text { Age of Empires } \\
\text { II } \quad \text { PC }\end{array}$ & $\begin{array}{l}\text { Skirmish Real } \\
\text { Time Strategy }\end{array}$ & Yes & 3 & 4 & 3 & 4 & 4 & 5 \\
\hline $\begin{array}{ll}\text { Elex } & \\
\end{array}$ & $\begin{array}{l}\text { Open World } \\
\text { Fantasy RPG }\end{array}$ & Yes & 3 & 4 & 1 & 3 & 4 & 4 \\
\hline $\begin{array}{c}\text { Stellaris } \\
-\quad \text { PC } \\
\end{array}$ & $\begin{array}{l}\text { Skirmish Real } \\
\text { Time Strategy }\end{array}$ & Yes & 4 & 4 & 3 & 4 & 4 & 5 \\
\hline $\begin{array}{l}\text { Into the Dead } \\
2 \begin{array}{l} \\
-\quad \text { Mobile }\end{array}\end{array}$ & $\begin{array}{l}\text { First Person } \\
\text { running } \\
\text { shooter }\end{array}$ & Yes & 2 & 4 & 1 & 2 & 3 & 5 \\
\hline $\begin{array}{r}\text { Dead Trigger } 2 \\
-\quad \text { Mobile } \\
\end{array}$ & $\begin{array}{l}\text { First Person } \\
\text { Shooter }\end{array}$ & Yes & 2 & 4 & 2 & 3 & 4 & 5 \\
\hline
\end{tabular}




\subsection{Survey Analysis}

In order to validate the proposed research question and hypothesis, the authors, had to use a variety of data analysis techniques to show that there was some correlation between whether accessibilities within games were needed at all; or do they need to be refined for effectively supporting deaf and hearing-impaired players while still the full immersive experience from games.

To validate this, the first set of tabular data to be analysed, was associated with whether any new games releases indicate accessibility on the actual box (see Table 3 ).

Referring to Table 3, it is clear that $69 \%$ of the test candidates asked does state that they could find relevant information about the game and what the accessibility features it does offer within the gaming environment after the initial launch. Using the sample Standard Deviation, the data does show a close spread of data to the mean. While the other $31 \%$ indicated that not often this information is shared, or knowledge about the actual game is limited.

Expanding from data analysis from Table 3, the next set of results looks at how accessibilities actually affects the game playability in general. Table 4 indicates $75 \%$ of the test candidates asked, that accessibility options did not actually hinder the game play at all; however, $25 \%$ did indicate not often. Referring to the Standard Deviation, there is a high spread of data, which points to one-sided statement.

The next Table 5 looks at exploring if modern game supplies any captions, and if so, does it actually support you or distract you as a player. $65 \%$ of test candidates indicated that whenever, they used games that had captions they never thought of them as a distraction. While exploring the data analysis further, $25 \%$ of the test candidate suggested that Not Often it would cause some sort of issue with them causing a distraction, and finally $13 \%$ agreed that sometimes it would cause some visual disruption. Referring to the Standard Deviation score, it is quite close the mean, which shows there a dispersed range of data, and still there is a positive support towards the question.

Another important aspect to exploring accessibility was how Game Caption Sound affects the gaming environment. Table 6 indicates that $19 \%$, of test candidates believe that, which offer this type of feature had not affected the game play at all, while $75 \%$ did suggest not often depending on game

Table 3. New Game Accessibility: Can you find out whether a new game is accessible for deaf players before purchasing?

\begin{tabular}{|l|l|l|}
\hline Never & 0 & Sample Standard Deviation:5.416 \\
\hline Not Often & 10 & Population Standard Deviation:4.69 \\
\hline Sometimes & 12 & Sample Size:4 \\
\hline Most of the time & 10 & Sample Variance:29.3331 \\
\hline total & 32 & Population Variance:21.9961 \\
\hline & & Mean:8 \\
\hline
\end{tabular}

Table 4. You weren't able to play a game at all because of accessibility

\begin{tabular}{|l|l|l|}
\hline Never & 24 & Sample Standard Deviation:11.3137 \\
\hline Not Often & 8 & Population Standard Deviation:9.798 \\
\hline Sometimes & 0 & Sample Size:4 \\
\hline Most of the time & 0 & Sample Variance: 127.9998 \\
\hline total & 32 & Population Variance:96.0008 \\
\hline & & Mean:8 \\
\hline
\end{tabular}


Table 5. Does modern games uses captions are they a distraction?

\begin{tabular}{|l|l|l|}
\hline Never & 20 & Sample Standard Deviation:8.641 \\
\hline Not Often & 8 & Population Standard Deviation:7.483 \\
\hline Sometimes & 4 & Sample Size:4 \\
\hline Most of the time & 0 & Sample Variance:74.6669 \\
\hline total & 32 & Population Variance:55.9953 \\
\hline & & Mean:8 \\
\hline
\end{tabular}

genre that they played. However, $6 \%$ of test candidates did believe that having this type of accessibility did dampen their game playability.

Reflecting upon the standard deviation results, the dispersed results are slightly high and point towards a biased view within the response about the test candidates indicating that game captions that use sound does not often hinder the gaming experience. Table 7 expands on the data analysis from Table 6 and looks at the subtitles within games, and how this directly affect accessibilities/game play.

It was noted by the test candidates that $84 \%$ of responses had indicated that subtitles did not often cause hinder or disruption to the main game play itself, while the $16 \%$ had suggested that it had caused some major issues. There was a high standard deviation point, associated with this research question and that was due to disperse spread of response.

Through the responses, it is clear that accessibilities do not affect the game play completely and in parts actually helps all genre of game players. For gamers who are disabled or might have a slight disability, this can be seen benefit as they too can be immersed into the game play as well. Modern game makers or even indie companies could make changes that would support more of wider range of audience as long as small changes are taken into consideration at the beginning of the developmental

Table 6. Games caption sounds of objects in the environment

\begin{tabular}{|l|l|l|}
\hline Never & 6 & Sample Standard Deviation:10.9545 \\
\hline Not Often & 24 & Population Standard Deviation:9.487 \\
\hline Sometimes & 2 & Sample Size:4 \\
\hline Most of the time & 0 & Sample Variance: 120.0011 \\
\hline Total & 32 & Population Variance:90.0032 \\
\hline & & Mean:8 \\
\hline
\end{tabular}

Table 7. Subtitles in the story-board were unreadable

\begin{tabular}{|l|l|l|}
\hline Never & 0 & Sample Standard Deviation:12.8841 \\
\hline Not Often & 27 & Population Standard Deviation:11.158 \\
\hline Sometimes & 5 & Sample Size:4 \\
\hline Most of the time & 0 & Sample Variance: 166 \\
\hline total & 32 & Population Variance: 124.501 \\
\hline & & Mean:8 \\
\hline
\end{tabular}


stage. However, standardisation must be adhered to or more research would be needed to validate this within different genre of games.

\subsection{Prototype Screenshots}

To support the data analysis section, a prototype was developed in Unreal to offer a variety of accessibility features and functionalities to offer and explore the "gamer-centricity needs". The prototype features a dialogue system that indicates the speaker as well as using a 48-pixel font size and dark opaque background behind the text see Figure 1.

Each line of text is displayed for 3.5 seconds and does not exceed 34 characters per line.

The closed caption supports up to two closed captions being displayed at the same time. It also has a big enough font size and dark opaque background to give contrast between text and background. It is used for enemies (Figure 2) but also for some atmospheric sounds (Figure 3).

Figure 3 displays a widget for a simple enemy indication system. This system creates an icon of an eye when an enemy has spotted the player.

The player also has icons placed at the top of the screen when the player has completed them to assist with accessibilities issues, please see Figure 4.

\section{DISCUSSION}

\subsection{Success of Study and Prototype}

As indicated in the literature to make games more "game-centric" to deaf and hearing-impaired gamers, certain aspects must be incorporated. These must include things like: subtitles (Barlet and Spohn, 2012, p. 5). The testing of modern day games showed that they all included the option for subtitles; however, most of the time they were missing in general good best practices (Hamilton 2015). According to the data analysis some games did some subtitles, or captions, like that in State of Decay (Undead Labs, 2013) but does not stick to 34 characters per line. Furthermore, the survey revealed that there is some correlation between how participants felt about their game experience and how subtitles were used in games. This particular study has discovered although subtitles are a common feature in video games they are not used to their full potential and impact gameplay experience. In addition, using guidelines provided for subtitles in television and adapting those into video games is going to greatly improve how subtitles are used in video games.

Figure 1. Prototype dialogue

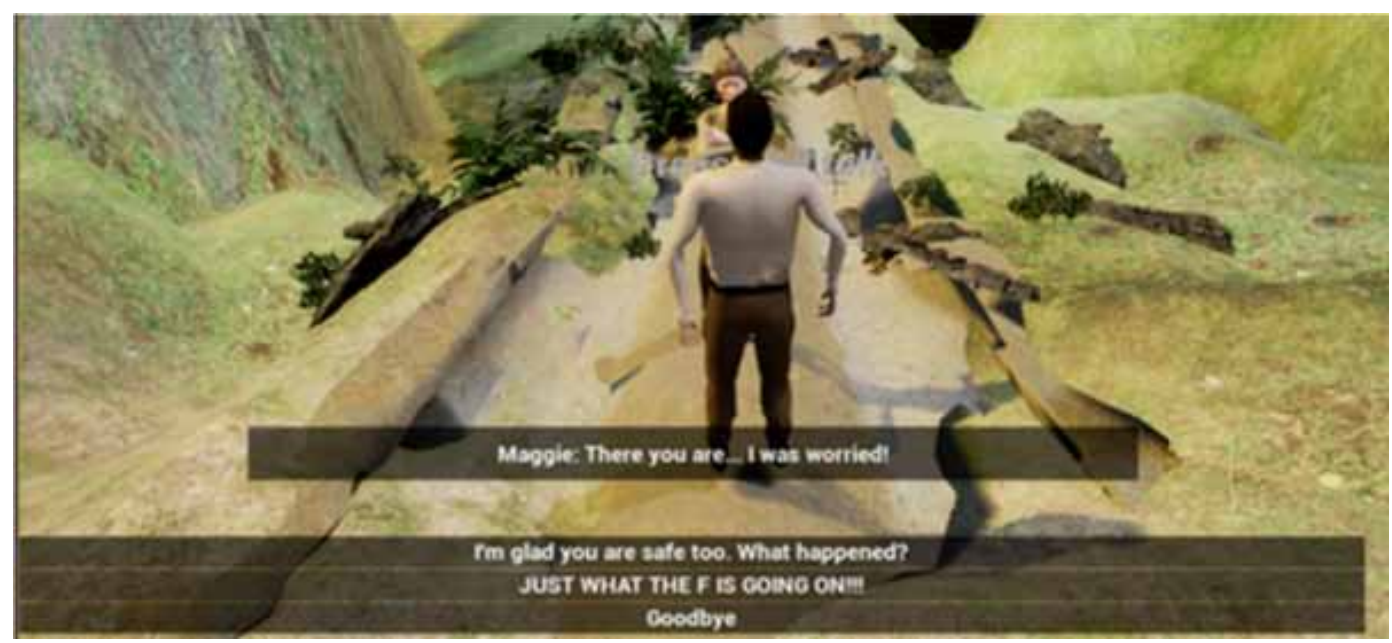




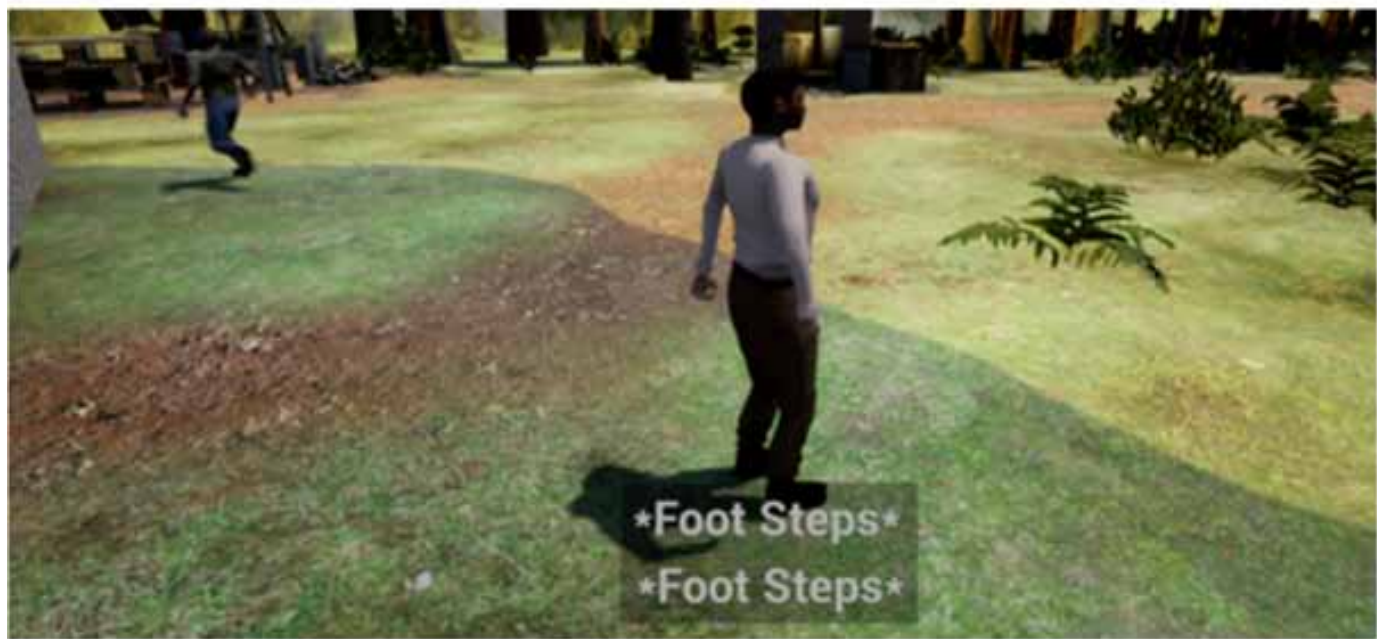

Prev *

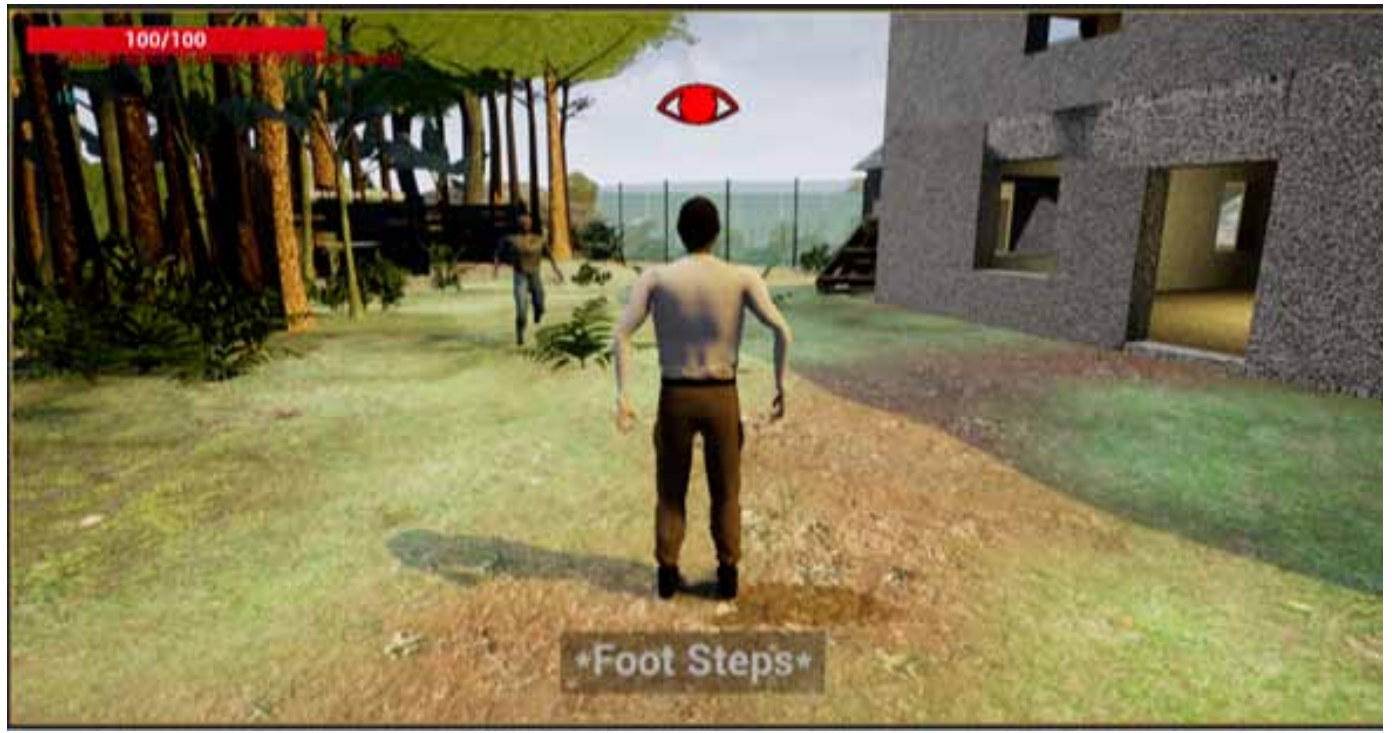

Closed captions are not commonly used among video games and games with non-linear and open environments. Enemies can be more difficult to overcome for deaf and hearing-impaired gamers. This is a definite disadvantage especially when enemies have ambient sound cues such as footsteps or groaning. As can be seen in games like Subnautica (Unknown Worlds Entertainment, 2018) where a fish emits a screaming sound while charging towards the player, a deaf player can be taken totally by surprise because there is no visual indication. The data analysis survey discovered possible correlations between how deaf and hearing-impaired players felt about missing visual information 

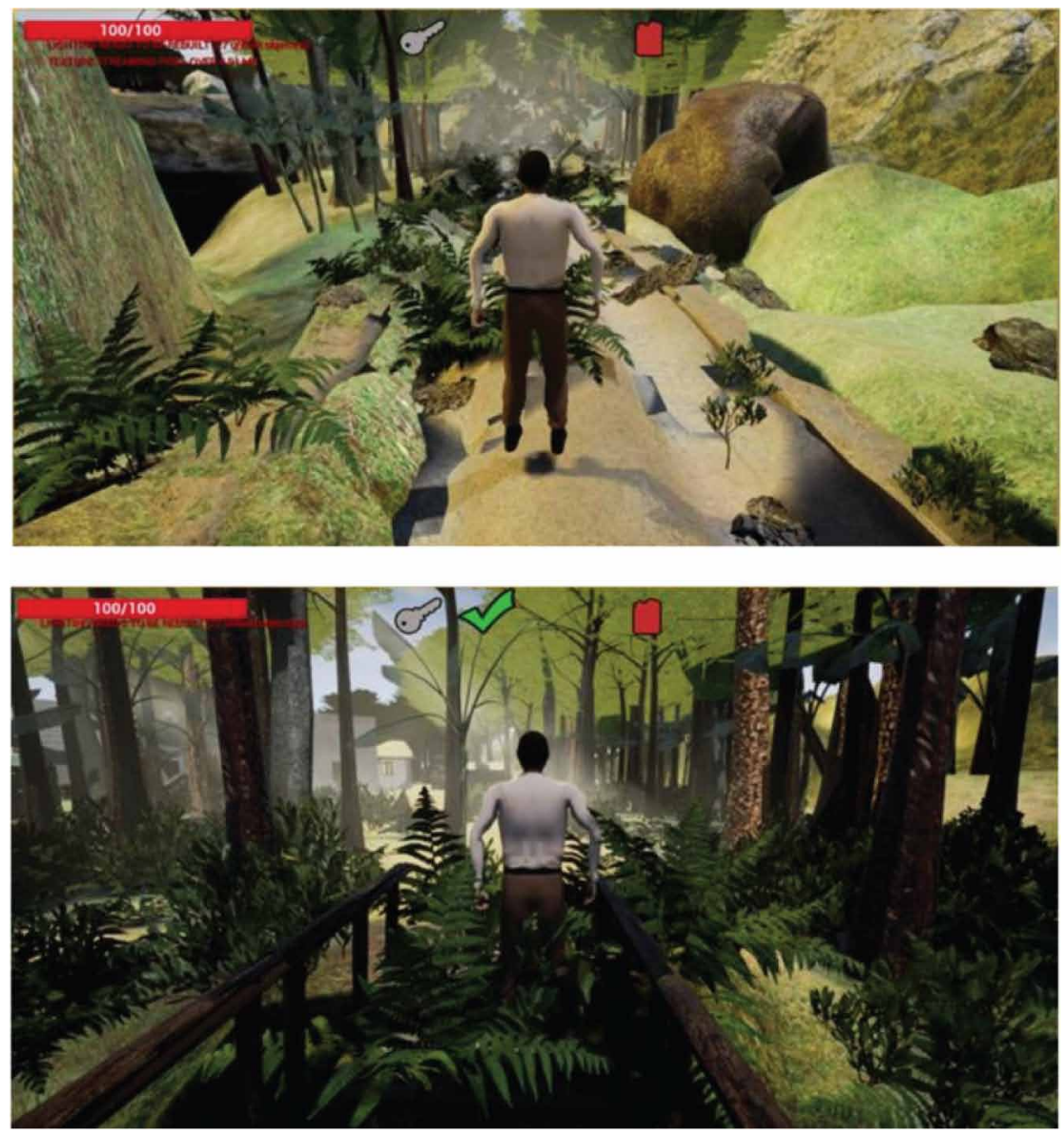

and closed captions and their experience of games. Using closed captions greatly improves the accessibility for deaf gamers and as Barlet and Spohn (2012, p. 38) state they should be used when enemies emit ambient sound cues.

There are also a number of other features that can help with accessibility such as a radar or minimap as presented in the previous chapter. Such a feature allows a player to anticipate enemy actions even for deaf and hearing-impaired players. Furthermore, an arrow indication of where an enemy is located and if the player has been spotted is an excellent way to improve gameplay without sound. As shown previously Far Cry 3 uses such a system and the mobile game Dead Trigger 2 uses an arrow indication where the icons colour gets stronger the closer an enemy is to the player (Madfinger Games, 2013). The literature review discovered that repeated and excessive stimulation makes a person less attentive and unable to distinguish what is important (Galitz, 2002, p. 68).

Colour coding such an indication system is necessary as it makes it a lot more effective. As it was stated in the literature review, colour coding important messages such as closed captions or a notification system like this needs to be left to designers. Text based closed captions on the bottom of the screen add to the atmosphere. 


\subsection{Strengths and Weaknesses of the Data}

The data discovered from testing games revealed different issues with games and accessibility for deaf and hearing-impaired players. This provided a basis to work on the prototype from. Innovative features are implemented into the prototype but the data also discovered that there already are useful features to improve accessibility. In contrast the data also revealed that although there are good features available many games do not implement them into their design.

The data acquired from the survey also discovered some interesting findings such as subtitles, closed captions and displayed information all affecting the play experience. Discovering this provided an insight into what features were most important to include in a game. However, the data would support the hypothesis more strongly if a larger number of participants would have been available.

\subsection{How Does the Project Confirm the Hypotheses?}

The discoveries made in the study show that although games provide accessibility functions and are playable most of the time for deaf and hearing-impaired players, the way accessibility functions are implemented can be improved greatly. Nevertheless, the data also shows that games have innovative features that can improve the experience for deaf and hearing-impaired players, which will assist with "gamer-centricity". Produced designs do; however, demonstrate that innovative features can be created to improve accessibility.

The findings in the data were used to implement accessibility for deaf and hearing-impaired gamers into the prototype. In addition, the designs for the prototype were produced in accordance with data found through the study and adjusted to provide accessibility. The prototype shows that accessibility features can be easily implemented when considered from the beginning of a project. All of the findings from this study confirm that games can improve their accessibility for deaf and hearing-impaired players. The findings in the literature review were taken into consideration while progressing through the project. Testing games on their accessibility proved that although games are playable without sound there are issues with the accessibility for deaf and hearing-impaired players. Additionally, the survey discovered how deaf and hearing-impaired gamers approach video games as well as their feelings and opinions about accessibility. Taking all of the findings into consideration it was possible to produce designs for a prototype that provides accessibility for deaf and hearingimpaired gamers. Furthermore, the actual prototype proved that accessibility for deaf and hearingimpaired players can be implemented efficiently when taken into consideration from the beginning of a project.

\section{CONCLUSION}

Throughout literature, it is clear that there have as been attempts to incorporate different disabilities features from the gaming industry, like subtitles and closed captions, improved accessibilities; however, there is still a need for refinements, in areas or a general standardisation, for particular genres, that would pave the way forward for new guidelines. These guidelines would be able to support gamers with a variety of different needs to those similar to television guidelines. This, however, could be difficult due to the nature and dynamic fluidness of user interactions and the genres available. Reflecting upon the data analysis within this journal, certain criteria's can be meet, that would and could greatly improve accessibility for deaf and hearing-impaired gamers.

The result from the data analysis does show that closed captions are a component that is necessary to provide accessibility for deaf and hearing-impaired gamers. The sample set used enabled the researchers to gather a preliminary data set, that indicated Deaf and hearing-impaired gamers were more focussed on visual aspects which is vital for developers to consider this. However, it was also found that adjustments to visuals need to be made according to the games style as well as considering available resources including the gaming world environment like, different lights and colours. 
Testing games on their accessibility gave insight into what features are being used by different types of games. The tests highlighted some good features as well as issues with accessibility of video games such as all of the tested games having subtitles but none following all of the best practices which affected the experience of playing the games. This was also noted in the data from the survey as there was correlation between the data on subtitles and play experience. Through the findings from testing it was possible to design and improve accessibility features as well as including the necessary tools into the prototype to make it accessible for deaf and hearing-impaired players.

Overall the study has successfully discovered patterns in the issues with accessibility of games for deaf and hearing-impaired players. Most of the time games have implemented accessibility features but not to the best standards and many of the issues could be easily overcome. Furthermore, it was possible to discover how to make games more accessible for deaf and hearing-impaired players. The data analysis showed what issues deaf and hearing-impaired gamers had with accessibility. Through this it was possible to provide more insight into what can be done to make games more accessible to deaf and hearing-impaired players such as including closed captions, effective subtitles and visual indications. In addition, the studied material and gathered data provided base knowledge to work on a prototype game and designs that considers accessibility for deaf gamers. Considering such features from the start showed that including them can be done a lot more efficiently when incorporated in the process from the beginning. 


\section{REFERENCES}

AFB. (2017). Children and youth with vision loss. Retrieved from http://www.afb.org/info/blindness-statistics/ children-and-youth/children-and-youth-with-vision-loss/235

Alcázar, J. A., \& Luján-Mora, S. (2017). Mobile Serious Games: An Accessibility Assessment for People with Visual Impairments. In TEEM 2017 Proceedings of the 5th International Conference on Technological Ecosystems for Enhancing Multiculturality. Why accessibility matter. Retrieved from http://gameaccessibilityguidelines. com/why-and-how/

Alcázar, J. A., Luján-Mora, S., \& Salvador-Ullauri, L. (2018). Inclusive Education: Mobile Serious Games for People with Cognitive Disabilities. Enfoque UTE, 9(1), 53-66. Retrieved from http://ingenieria.ute.edu.ec/ enfoqueute/

Barlet, M., \& Spohn, S. (2012). Includification: A Practical Guide To Game Accessibility. The Able Gamers Foundation.

Beeston, J., Power, C., Cairns, P., \& Barlet, M. 2018. Characteristics and Motivations of Players with Disabilities in Digital Games. arXiv:1805.11352

Betke, M., Gips, J., \& Fleming, P. (2002). The camera mouse: Visual tracking of body features to provide computer access for people with severe disabilities. IEEE Transactions on Neural Systems and Rehabilitation Engineering, 10(1), 1-10. doi:10.1109/TNSRE.2002.1021581 PMID:12173734

CDC.gov. (2009). vision loss burden. Retrieved from Https://Www.Cdc.Gov/Visionhealth/Basic_Information/ Vision_Loss_Burden.Htm

Costello, R. (2017). Gaming Innovations in Higher Education: Emerging Research and Opportunities. Hershey, PA: IGI Global.

Costello, R. 2018. Future Direction of Gamification Within Higher Education. In Virtual and Augmented Reality: Concepts, Methodologies, Tools, and Applications (pp. 1721-1741). IGI Global.

Costello, R. \& Lambert, M. (2018). Motivational influences for Higher Education (HE) Students. Journal of Online Pedagogy and Course Design.

Cresswell, J. W. (2014). Research Design Qualitative, Quantitative and Mixed Methods Approaches. Atlanta, GA: Sage.

Creswell, J. (2007). Qualitative Inquiry \& Research Design. Sage Publishing.

de Jong, S. (2008). The How's and Why's of Level Design (2nd ed.). Hourences.

Dong, M., 2016. Towards Understanding and Developing Virtual Environments to Increase Accessibilities for People with Visual Impairments.

Driscoll, D. L. (2011). Introduction to Primary Research: Observations, Surveys, and Interviews. In C. Lowe \& P. Zemliansky (Eds.), Writing Spaces (2nd ed.). Parlor Press.

Dudovskyi, J. (2017). Quantitative Data Analysis. Retrieved from https://research-methodology.net/researchmethods/data-analysis/quantitative-data-analysis/

Duffy, S., Price, S., Volpe, G., Marshall, P., Berthouze, N., Giulia Cappagli, G., . . Gori, M. (2017). WeDraw: using multisensory serious games to explore concepts in primary mathematics. In Proceedings of the 13th international conference on technology in mathematics teaching (ICTMT 13).

Feil, J., \& Scattergood, M. (2005). Beginning Game Level Design. Thomson Course Technology.

FromSoftware. (2016). Dark Souls 3. Tokyo, Japan: Bandai Namco Entertainment.

Galitz, W. O. (2002). The Essential Guide to User Interface Design (2nd ed.). John Wiley \& Sons, Inc.

Game Accessibility Guidelines. (2012). A straightforward reference for inclusive game design http:// gameaccessibilityguidelines.com/ 
Griffiths, G. (2009). Subtitles: Increasing Game Accessibility, Comprehension. Retrieved from https://www. gamasutra.com/view/feature/132315/subtitles_increasing_game_.php

Hamilton, I. (2015). How to do subtitles well - basics and good practices. Gamasutra. Retrieved from https:// www.gamasutra.com/blogs/IanHamilton/20150715/248571/How_to_do_subtitles_well_basics_and_good_ practices.php

Heron, M. (2012). Inaccessible through oversight: The need for inclusive game design. The Computer Games Journal, 1(1), 29-38. doi:10.1007/BF03392326

Hidden Path Entertainment. (2012). Age of Empires II: HD Edition. Redmond, WA: Microsoft.

Kothari, S. M. (2004). Research Methodology: Methods and Techniques (2nd ed.). New Age International Publishers.

Lahav, O., Gedalevitz, H., Battersby, S., Brown, D., Evett, L., \& Merritt, P. (2018). Virtual environment navigation with look-around mode to explore new real spaces by people who are blind. Disability and Rehabilitation, 40(9), 1072-1084. doi:10.1080/09638288.2017.1286391 PMID:28637136

Linden, M., Habib, T., \& Radojevic, V. (1996). A controlled study of the effects of EEG biofeedback on cognition and behavior of children with attention deficit disorder and learning disabilities. Biofeedback and Self-Regulation, 21(1), 35-49. doi:10.1007/BF02214148 PMID:8833315

Little, T. D. (2013). The Oxford Handbook of Quantitative Methods. Oxford University Press.

Madfinger Games. (2013). Dead Trigger 2. Brno, Czech Republic: Digital Download. Android. Madfinger Games.

Mäenpää, H. (2014). Optimizing Games for the hearing impaired [Bachelor Thesis in Media and Arts]. Tampere University of Applied Sciences.

Mäenpää, H. (2014). Optimizing Games for the hearing impaired. Bachelor Thesis in Media and Arts, Tampere University of Applied Sciences.

Morelli, T., Foley, J., \& Folmer, E. (2010). Vi-bowling: a tactile spatial exergame for individuals with visual impairments. In Proceedings of the 12th international ACM SIGACCESS conference on Computers and accessibility (pp. 179-186). ACM. doi:10.1145/1878803.1878836

National Library Service for the Blind. (2018). Video Gaming Accessibility. Retrieved from https://www.loc. gov/nls/resources/general-resources-on-disabilities/video-gaming-accessibility/

Ninja Theory. (2017). Hellblade: Senua's Sacrifice. Digital Download. PC. Cambridge, England: Ninja Theory.

Paradox Development Studio. (2016). Stellaris. Digital Download. PC. Stockholm, Sweden: Paradox Interactive.

Piranha Bytes. (2017). ELEX. Digital Download. PC. Vienna, Austria: THQ Nordic.

Prates, R. O., \& Chaimowicz, L. 2011, November. An analysis of information conveyed through audio in an FPS game and its impact on deaf players experience. In 2011 Brazilian Symposium on Games and Digital Entertainment (SBGAMES) (pp. 53-62). IEEE.

RNIB. (2016). Video-computer-games-people-vision-impairment. Retrieved from https://www.rnib.org.uk/ nb-online/video-computer-games-people-vision-impairment

Rogers, S. (2010). Level Up! The guide to great video game design. John Wiley \& Sons, Ltd.

Rouse, R. (2005). Game Design Theory \& Practice (2nd ed.). Wordware Publishing.

Schell, J. (2008). The Art of Game Design. Morgan Kaufmann Publishers. doi:10.1201/9780080919171

Tashakkori, A., \& Teddlie, C. (2003). Handbook of Mixed Methods in Social \& Behavioral Research. Thousand Oaks, CA: Sage.

Ubisoft Montreal. (2012). Far Cry 3. Digital Download. PC. Montreuil, France: Ubisoft.

Ubisoft Montreal. (2013). Assassins Creed IV: Black Flag. Montreuil, France: Digital Download. Windows. Ubisoft. 
UKIE. 2018. The games industry in numbers. Retrieved from https://ukie.org.uk/research

Undead Labs. (2013). State of Decay. Digital Download. PC. Redmond, WA: Microsoft Studios.

Unknown Worlds Entertainment. (2018). Subnautica. Digital download. PC. San Francisco, CA: Unknown Worlds Entertainment.

Valve Corporation. (2004). Half Life 2. Digital Download. Windows/Mac. Bellevue, WA: Valve Corporation.

Williams, G. F. (2009). Online Subtitling Editorial Guidelines v1.1. BBC. Retrieved from http://www.bbc.co.uk/ guidelines/futuremedia/accessibility/subtitling_guides/online_sub_editorial_guidelines_vs1_1.pdf

Winchester, C. L., Salji, M. J., \& Kasivisvanathan, V. (2017). Gathering preliminary data. Retrieved from http:// eprints.gla.ac.uk/150781/1/150781.pdf

Robert Costello has worked as a researcher within the field of online learning, and in particular (personalised \& adaptive learning) while incorporating learning theories and Adaptive Information Retrieval (AIR) since 2005. His research trends do vary to incorporate Postgraduates, which has mostly involved tailoring system designs for community collaboration, MLearning and gamification within Higher Education. Over the last 13 he has taught a variety of computing modules in Further Education to Higher Education. Currently he is a HE Programme Leader for the BSc Hons Top-up degree.

Murray Lambert received a BA (Hons) Creative Practice in 2009 and is presently working on an MA in Animation. Currently he is employed as a Senior Lecturer within the Digital Technologies department of Newcastle College. He delivers on a range of computing degrees, primarily on the games design and development courses. Outside of teaching, he provides 3D modelling and animation services on a freelance basis.

Florian Kern realized after being fed up of working in recruitment and interviewing for a job at a big games companies and customers service, that he should study something to do with games. This lead to recieving a Bsc Hons Applied Computing Games and Digital Media at Newcastle College. Currently, they are studying MA Games Design at Teesside University and mostly work within Unreal Engine 4. Outside of studying, making and playing video games they also enjoy music and djing, photography especially nature and keeping exotic pets. 